\title{
The fatty acid pattern of dietary fat influences the oral bioavailability of the flavonol quercetin in pigs
}

\author{
Stephanie Lesser ${ }^{1}$, Rainer Cermak $^{2} *$ and Siegfried Wolffram ${ }^{3}$ \\ ${ }^{1}$ Department of Nutrition and Food Sciences, Nutritional Physiology, University of Bonn, Endenicher Allee 11-13, \\ D-53115 Bonn, Germany \\ ${ }^{2}$ Institute of Veterinary Physiology, University of Leipzig, An den Tierkliniken 7, D-04103 Leipzig, Germany \\ ${ }^{3}$ Institute of Animal Nutrition and Physiology, Christian-Albrechts-University Kiel, D-24098 Kiel, Germany
}

(Received 15 February 2006 - Revised 24 July 2006 - Accepted 31 July 2006)

\begin{abstract}
We have shown recently that dietary fat content influences the bioavailability of the flavonol quercetin. In the present study, the influence of the fatty acid pattern of dietary fats on the oral bioavailability of quercetin was investigated. Quercetin ( $30 \mu \mathrm{mol} / \mathrm{kg}$ body weight) was administered to growing pigs $(n 6)$ in test meals consisting either of $200 \mathrm{~g}$ of a standard pig diet ( $2 \%$ crude fat) or of the same diet supplemented with $15 \mathrm{~g}$ fat $/ 100 \mathrm{~g}$ diet using either medium-chain (MCT) or long-chain fatty acid triacylglycerols (LCT). Blood samples were drawn repeatedly over a period of $24 \mathrm{~h}$ and analysed by HPLC. In addition, the influence of the different diets on gastric emptying was investigated in rats. In pigs, the bioavailability of quercetin was measured by quantifying its plasma metabolites with an intact flavonol structure. Bioavailability was enhanced by $38 \%(P<0 \cdot 05)$ and $12 \%(P>0.05)$ after intake with the MCT and LCT diets, respectively, compared to the standard diet. Maximum plasma concentrations of quercetin were reached significantly later with the MCT diet than with the LCT or the standard diet $(P<0 \cdot 05)$. No differences in dry matter of the gastric content were observed $60 \mathrm{~min}$ after intake of the experimental diets in rats. Thus, administration of quercetin together with a diet containing MCT fat enhances the bioavailability of the flavonol. Absorption of quercetin was delayed significantly with this diet. However, this was probably not due to slower gastric emptying of the MCT diet.
\end{abstract}

Quercetin: Bioavailability: Fat: Pig

Flavonoids are polyphenolic secondary metabolites that occur ubiquitously in higher plants. Their abundance in the human diet has led to increasing interest in their bioavailability and biological properties. Flavonoids exert biological activities that are mainly related to their ability to influence various enzymes and/or to their antioxidant properties (Middleton et al. 2000). Detailed assessment of the bioavailability of putatively beneficial polyphenolic food constituents is vital for the evaluation of health effects in man and animals (Manach et al. 2005). The flavonol quercetin is one of the major representatives of flavonoids in many edible plants (Herrmann, 1988; Hertog et al. 1992) and also one of the most studied.

Our group has been investigating the bioavailability of quercetin in pigs for several years. The gastrointestinal as well as the circulatory system in this species is similar to that in man; thus, the pig is considered a relevant model species (Almond, 1996). In a previous study, the oral bioavailability of quercetin aglycone from a test meal was enhanced by $57 \%$ by the addition of $15 \%$ (w/w) fat to a low-fat standard pig diet (Lesser et al. 2004). We speculated whether the enhancement of quercetin bioavailability was due to the better solubility of the relatively lipophilic quercetin aglycone in the intestinal tract in the presence of fat (Azuma et al. 2002). In this case, an increased absorption from fat-containing diets should be largely independent of the type of dietary fat. Another possible explanation could be the generation of chylomicrons in the intestinal mucosa. Dietary fat mainly comprises triacylglycerols with long-chain fatty acids (chain length $>\mathrm{C}_{12}$ ). After luminal hydrolysis, mucosal uptake and resynthesis of triacylglycerols, long-chain fatty acid triacylglycerols (LCT) are incorporated into chylomicrons and are consecutively transported via the lymph. By contrast, medium-chain fatty acid triacylglycerols (MCT, chain length $\mathrm{C}_{8}-\mathrm{C}_{12}$ ) are hydrolysed and predominantly exported from the enterocytes as NEFA into the mesenterical blood; they reach the liver through the portal vein (Bloom et al. 1951; Hashim et al. 1964; for review, see Harkins \& Sarett, 1968). Transport together with LCT within chylomicrons via the lymphatic vessels (Murota \& Terao, 2005) could enhance quercetin bioavailability by bypassing the liver, thereby reducing biliary elimination during the first liver passage (the firstpass effect). If this was the case, mainly fats containing LCT should increase the bioavailability of flavonols but not fats comprising MCT because of the different handling of

Abbreviations: AUC, area under the curve; BW, body weight; CCK, cholecystokinin, $c_{\max }$, maximum plasma concentration; LCT, long-chain fatty acid triacylglycerols; MCT, medium-chain fatty acid triacylglycerols; $t_{\max }$, time at maximum plasma concentration.

* Corresponding author: Rainer Cermak, fax +49 341 9738097, email cermak@vetmed.uni-leipzig.de 
LCT and MCT during intestinal absorption (Harkins \& Sarett, 1968). To differentiate between these two possibilities (i.e. better solubility $v$. bypassing of the liver), we fed quercetin ( $30 \mu \mathrm{mol} / \mathrm{kg}$ body weight (BW)) to pigs with test meals consisting of a low-fat pig diet or of the same diet enriched with either $15 \mathrm{~g}$ MCT or LCT fat $/ 100 \mathrm{~g}$ diet. The quantity of quercetin we administered with the test meals is similar to the amount that can be ingested by man in a meal rich in onions or apples (Hollman et al. 1997).

\section{Materials and methods}

\section{Animals and diets}

Cross-bred (Deutsche Landrasse $\times$ Deutsches Edelschwein) growing male castrated pigs $(n 6)$ with a BW of $30-35 \mathrm{~kg}$ were purchased from a local farmer. The pigs were surgically equipped with permanent catheters (Cook Deutschland GmbH, Mönchengladbach, Germany) placed in the left jugular vein. The pigs were restrictively fed ( $80 \%$ of voluntary feed intake) with a commercial pig diet composed mainly of wheat, barley and defatted soybean meal (Plambeck Kraftfutter, Brügge, Germany). The composition of this diet (designated as standard diet) is shown in Table 1. Test meals were isoenergetic and consisted of the standard diet or of the same diet enriched with either $15 \mathrm{~g}$ lard or synthetic MCT oil/100 g diet (w/w; designated as LCT or MCT diet, respectively). The fatty acids of the MCT oil consisted solely of octanoic and decanoic acid with a mean chain length of $\mathrm{C}_{88.8}$. The lard was composed of LCT with a mean chain length of $\mathrm{C}_{17.3}$, as determined from the saponification number. Predominant fatty acids in lard are C18: 1 (43 g/100 g), C16: 0 (24 g/100 g), C18:0 $(14 \mathrm{~g} / 100 \mathrm{~g})$ and $\mathrm{C} 18: 2(9 \mathrm{~g} / 100 \mathrm{~g})$, with no fatty acids of less than 14 carbon atoms (Belitz \& Grosch, 1992). Commercial lard was obtained from Fischermanns $\mathrm{GmbH}$ (Duisburg, Germany), and the MCT oil was a kind gift from Unilever (Vlaardingen, the Netherlands). Vitamins and minerals where supplemented according to the recommendations of the German Society of Nutritional Physiology (Ausschuss für Bedarfsnormen der Gesellschaft für Ernährungsphysiologie, 1987). Water was supplied ad libitum for intake by nipple drinkers.

Additionally, eighteen male CD rats (Charles River, Sulzfeld, Germany) with a mean BW of approximately $250 \mathrm{~g}$ were used to

Table 1. Composition of diets*

\begin{tabular}{|c|c|c|c|}
\hline & \multicolumn{3}{|c|}{ Diet } \\
\hline & Standard & LCT & MCT \\
\hline \multicolumn{4}{|l|}{ Components (g/kg diet) } \\
\hline Dry matter & $857 \cdot 2$ & $882 \cdot 7$ & 881.4 \\
\hline Crude fat & $16 \cdot 7$ & $159 \cdot 2$ & $162 \cdot 8 \dagger$ \\
\hline Crude protein & $172 \cdot 3$ & $140 \cdot 5$ & $144 \cdot 8$ \\
\hline Ash-free NDF & $147 \cdot 3$ & $126 \cdot 5$ & $124 \cdot 6$ \\
\hline NFC & $468 \cdot 6$ & $413 \cdot 3$ & $407 \cdot 6$ \\
\hline Starch & $426 \cdot 1$ & $365 \cdot 2$ & $369 \cdot 6$ \\
\hline Gross energy (MJ/kg diet) & $15 \cdot 6$ & $19 \cdot 0$ & $19 \cdot 1$ \\
\hline \multicolumn{4}{|c|}{$\begin{array}{l}\text { LCT, long-chain fatty acid triacylglycerols; MCT, medium-chain fatty } \\
\text { acid triacylglycerols; NDF, neutral detergent fibre; NFC, non-fibre } \\
\text { carbohydrates. } \\
\text { * Isoenergetic amounts of each diet were fed: } 200 \mathrm{~g} \text { of the standard } \\
\text { diet, and } 162 \mathrm{~g} \text { each of LCT and MCT diets. } \\
\text { † Composed of } 90 \% \text { MCT and } 10 \% \text { LCT. }\end{array}$} \\
\hline
\end{tabular}

investigate gastric emptying after consumption of the specific diets. The rats were housed individually and kept on a $12 \mathrm{~h}$ light/dark cycle. They were accustomed to eating the standard pig diet for one week before the experiment.

The experiments were approved by the Animal Welfare Officer of the University of Kiel and by the relevant legal authorities (Ministry of Agriculture and Environment of Schleswig-Holstein).

\section{Experimental procedure}

Bioavailability in pigs. Each pig received a dose of $30 \mu \mathrm{mol}$ quercetin $/ \mathrm{kg} \mathrm{BW}$ that was mixed into the respective test meal directly before offering the test meal. The animals consumed the meal within 5-10 min. Test meals were isoenergetic. Fifteen blood samples $(8 \mathrm{ml}$ each) were collected from each pig over a period of $24 \mathrm{~h}$ after intake of the test meal. A wash-out period of $24 \mathrm{~h}$ was placed between the last sampling point and the application of the following test meal. Thus, the three different quercetin-containing test meals were fed consecutively at intervals of $48 \mathrm{~h}$.

Gastric emptying in rats. Two days before the experiment, the rats were allocated to three groups (six per group) and trained to eat meals of $5 \mathrm{~g}$ of the respective test diets (standard, LCT or MCT) within 15 min twice a day (at the beginning and end of the dark period). No further food was provided during this period. The BW did not differ between the groups (253.4 (SEM 5.0), 256.3 (SEM 6.3) and 254.5 (SEM 4.5) g for the standard, LCT and MCT groups, respectively). After fasting for $11 \mathrm{~h}$ (water allowed), the rats were fed the respective test meals $(5 \mathrm{~g}$ containing $0.5 \mathrm{mmol}$ quercetin $/ 100 \mathrm{~g}$ diet, equimolar to the concentration in the standard diet pig test meal). The rats were anaesthetized with $\mathrm{CO}_{2} 1 \mathrm{~h}$ after intake of the meals and immediately decapitated. Blood was collected, the abdominal cavity opened, and the stomach proximally and distally ligated and removed. The stomach content was collected by rinsing the stomach with $2 \mathrm{ml}$ of pure water. The gastric content was dried $\left(106^{\circ} \mathrm{C}\right)$ to a constant weight. Dry matter was related to the dry matter of the respective diet ingested.

\section{Processing of plasma samples and HPLC analysis}

Blood samples from pigs and rats were drawn into heparinized containers and centrifuged immediately $\left(1500 \mathrm{~g}, 10 \mathrm{~min}, 4^{\circ} \mathrm{C}\right)$. Plasma was stored at $-70^{\circ} \mathrm{C}$ until analysis by HPLC as described previously (Hollman et al. 1996; Ader et al. 2000; Cermak et al. 2003). Extraction of flavonols from plasma samples was performed according to Morand et al. (1998). An aliquot $(980 \mu \mathrm{l})$ of the plasma sample was spiked with $20 \mu \mathrm{l}$ rhamnetin (internal standard, $50 \mu \mathrm{g} / \mathrm{ml}$ in methanol), acidified ( $\mathrm{pH} \mathrm{5)}$ with $100 \mu \mathrm{l}$ acetic acid $(0.583 \mathrm{~mol} / \mathrm{l})$, and subsequently treated with a mixture of $10^{4}$ units $\beta$-glucuronidase/ $4 \times 10^{2}$ units sulfatase (crude extract from Helix pomatia, Sigma Aldrich). After incubation for $1 \mathrm{~h}$ at $37^{\circ} \mathrm{C}$, the flavonol aglyca quercetin, kaempferol, isorhamnetin and tamarixetin were extracted simultaneously with $5.5 \mathrm{ml}$ acetone. The mixture was centrifuged at $3700 \mathrm{~g}$ for $45 \mathrm{~min}$ and the supernatant evaporated under partial vacuum at $45^{\circ} \mathrm{C}$ to dryness. The residue was resolved in $200 \mu \mathrm{l}$ methanol, $77.5 \mu \mathrm{l}$ nanopure $\mathrm{H}_{2} \mathrm{O}$ 
and $22.5 \mu \mathrm{HCl}(10 \mathrm{~mol} / \mathrm{l})$. For HPLC analysis $30 \mu \mathrm{l}$ were injected onto a C-18 Kromasil 100 column (dimensions: $250 \times 4 \mathrm{~mm}$, particle size $5 \mu \mathrm{m})$ guarded by a C-18 Inertsil ODS-2 precolumn (Jasco, Groß-Umstadt, Germany). The eluent $(1 \mathrm{ml} / \mathrm{min})$ was composed of $0.025 \mathrm{~mol} / 1 \mathrm{NaH}_{2} \mathrm{PO}_{4}$, $\mathrm{pH} 2 \cdot 4$, acetonitrile and methanol $(68: 27: 5 \mathrm{v} / \mathrm{v} / \mathrm{v})$. The column effluent was mixed with $0.4 \mathrm{ml} / \mathrm{min} 1.0 \mathrm{~mol} / 1$ $\mathrm{Al}\left(\mathrm{NO}_{3}\right)_{3}$ in methanol containing $7.5 \%(\mathrm{v} / \mathrm{v})$ acetic acid in a post-column reactor. The column and the reactor were placed in a column oven at $30^{\circ} \mathrm{C}$. The fluorescence of the ensuing flavonol-metal complex was measured at $485 \mathrm{~nm}$ using a fluorescence detector with an excitation wavelength of $422 \mathrm{~nm}$. The limit of detection was $5-7 \mathrm{nmol} / \mathrm{l}$. Inter-analysis and inter-day variances were within $5 \%$. Standards were prepared with pure flavonols (Carl Roth GmbH, Karlsruhe, Germany) and treated as described earlier. Identification of peaks obtained in plasma samples was performed using the retention times of the pure flavonols (standards).

\section{Statistical analyses}

Data are presented as means with their standard errors (SEM). The area under the plasma concentration-time curve (AUC) was determined according to the linear trapezoidal rule. For each pig and treatment, total bioavailability $\left(\mathrm{AUC}_{\mathrm{total}}\right)$ was calculated by summing the AUC values of quercetin and its metabolites with an intact flavonol structure (isorhamnetin and tamarixetin). AUC data, maximum plasma concentration $\left(c_{\max }\right)$ and time at maximum plasma concentration $\left(t_{\max }\right)$ were analysed using repeated measures one-way ANOVA. The amount of dry matter from the gastric content and the plasma flavonol concentrations of the rats were analysed using one-way ANOVA. Tukey's multiple comparison was applied as post-test (Graphpad Prism 4, Graphpad Software Inc., San Diego, CA, USA). A $P$ value $<0.05$ was considered significant.

\section{Results}

\section{Bioavailability in pigs}

After administration of quercetin with the test meals to pigs, metabolites with an intact flavonol structure appeared in plasma within $30 \mathrm{~min}$. Plasma levels of flavonols decreased below the detection limit within $24 \mathrm{~h}$. In accordance with previous studies (Cermak et al. 2003; Lesser et al. 2004), the main metabolite after $\beta$ glucuronidase/sulfatase treatment of the pig plasma samples was quercetin, while isorhamnetin (3'-O-methyl quercetin) and tamarixetin (4'-O-methyl quercetin) were found in a proportion of approximately $10 \%$ each, irrespective of the dietary treatment.

After intake of quercetin with the standard diet, the mean peak plasma concentration $\left(c_{\max }\right)$ was reached $95 \min \left(t_{\max }\right)$ after intake (Table 2). Thereafter, quercetin levels with the standard diet decreased continuously until they were below the detection limit after $24 \mathrm{~h}$ (Fig. 1).

When the flavonol was administered together with the LCT diet, the plasma concentrations of quercetin peaked after $65 \mathrm{~min}$. This was not, however, significantly different from the intake with the standard diet (Table 2). At $8 \mathrm{~h}$ after meal intake, the plasma quercetin concentrations were 0.053 (SEM $0 \cdot 008$ ) and 0.029 (SEM 0.007) $\mu \mathrm{mol} / \mathrm{l}$ for the LCT and standard diets, respectively.

After administration of quercetin together with the MCT diet, flavonol plasma concentrations rose steadily over 170 min until peak level (Table 2), and thereafter declined continuously. At $8 \mathrm{~h}$ after intake, the mean plasma concentration was still higher (0.061 (SEM 0.009) $\mu \mathrm{mol} / \mathrm{l})$ than after intake with the standard diet $(P<0.05)$. At $12 \mathrm{~h}$ after meal intake, the mean plasma concentrations in all groups were low (Fig. 1). The maximum plasma concentrations of quercetin after intake with the three different diets were not significantly different. The total oral bioavailability $\left(\mathrm{AUC}_{\mathrm{total}}\right)$ of quercetin, however, was significantly higher after intake of quercetin with the MCT diet than after intake with the standard and LCT diets (Table 2).

\section{Gastric emptying in rats}

Within $15 \mathrm{~min}$, the rats consumed $5 \mathrm{~g}$ of the experimental diets, which contained the same dietary concentration of quercetin as in the original pig test meals. This resulted in an intake of about $100 \mu \mathrm{mol}$ quercetin/ $\mathrm{kg} \mathrm{BW}$. One hour after consumption of the meals, blood samples and gastric contents were collected. Dry matter of the gastric contents did not differ in weight (Fig. 2(a)). About $80 \%$ of dry matter consumed remained in the stomach $1 \mathrm{~h}$ after meal intake.

The flavonol plasma concentrations (sum of quercetin and methylated metabolites) $1 \mathrm{~h}$ after intake of quercetin tended to be lower after intake with the MCT diet (Fig. 2(b);

Table 2. Pharmacokinetic parameters and relative bioavailability of quercetin in pigs after intake of quercetin in test meals differing in their fat content and/or fatty acid pattern*

\begin{tabular}{|c|c|c|c|c|c|c|c|}
\hline \multirow[b]{2}{*}{ Diet† } & \multicolumn{2}{|c|}{$c_{\max }(\mu \mathrm{mol} / \mathrm{l})$} & \multicolumn{2}{|c|}{$t_{\max }(\min )$} & \multicolumn{2}{|c|}{$\mathrm{AUC}_{\text {total }}(\min \times \mu \mathrm{mol} / \mathrm{l})$} & \multirow{2}{*}{$\begin{array}{c}\text { Relative } \\
\text { bioavailability (\% }\end{array}$} \\
\hline & Mean & SEM & Mean & SEM & Mean & SEM & \\
\hline Standard & 0.323 & 0.038 & $95 \cdot 0^{a}$ & $18 \cdot 0$ & $86 \cdot 6^{b}$ & 11.3 & 100 \\
\hline LCT & 0.334 & 0.034 & $65 \cdot 0^{\mathrm{a}}$ & $5 \cdot 0$ & $96 \cdot 7^{b}$ & 8.5 & 112 \\
\hline MCT & 0.288 & 0.030 & $170.0^{\mathrm{b}}$ & $20 \cdot 0$ & $119 \cdot 7^{\mathrm{a}}$ & 8.7 & 138 \\
\hline
\end{tabular}

$c_{\max }$, maximum plasma concentration of quercetin; $t_{\max }$, time between administration of test meal and the appearance of maximum plasma concentration of quercetin; $\mathrm{AU} \mathrm{C}_{\mathrm{total}}$, area under the plasma concentration-time curve from 0 to $24 \mathrm{~h}$ for the sum of quercetin and its metabolites isorhamnetin and tamarixetin; LCT, long-chain fatty acid triacylglycerols; MCT, medium-chain fatty acid triacylglycerols.

a,b Mean values within a column with unlike superscript letters were significantly different $(P<0.05)$.

*Values are for means of six pigs for each dietary treatment.

†For composition of diets, see Table 1. 


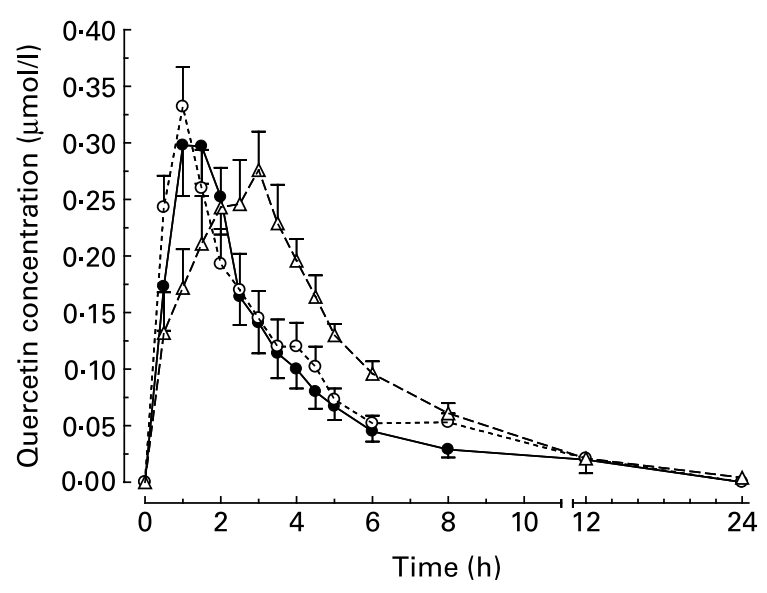

Fig. 1. Plasma concentration-time curves of the main metabolite quercetin after oral administration of quercetin $(30 \mu \mathrm{mol} / \mathrm{kg}$ body weight) to pigs in test meals that differed in their fat content and/or fatty acid pattern. Values are means for six pigs, with standard errors of the mean represented by vertical bars. For composition of diets, see Table 1. (•) Standard diet; (०) long-chain fatty acid triacylglycerol (LCT) diet; $(\Delta)$ medium-chain fatty acid triacylglycerol (MCT) diet.

$P=0 \cdot 073)$. In rat plasma the pattern of deconjugated quercetin metabolites differed from that found in pigs. In rats, the relative proportions of quercetin, isorhamnetin and tamarixetin in plasma were 52.3 (SEM 1.3), 45.0 (SEM 1.4) and 4.9 (SEM 0.1) $\%$, respectively ( $n 18$ ). As observed in pigs, however, dietary treatment did not influence the proportions of methylated metabolites.

\section{Discussion}

In previous experiments, the addition of fat to a low-fat diet increased quercetin bioavailability from quercetin-3-O-glucoside as well as from quercetin aglycone (Lesser et al. 2004). Research during the past decade has shown that any quercetin glycosides present in food have to be deglycosylated prior to absorption into the circulation (Cermak et al. 2003; Murota \& Terao, 2003). Thus, we considered that the aglycone that was used in the present study is a representative flavonol of other nutritionally relevant quercetin glucosides that are (a)

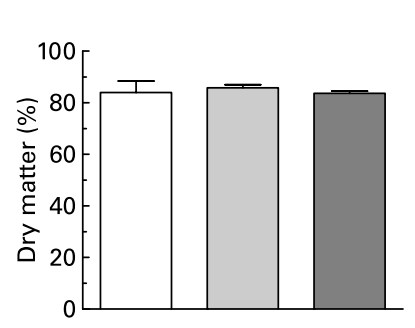

(b)

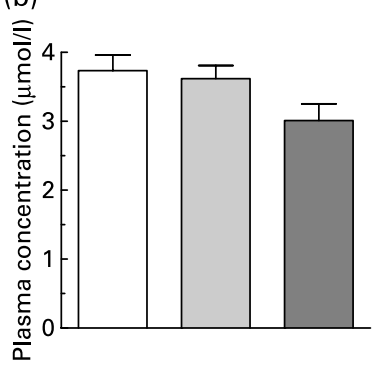

Fig. 2. (a) Gastric content (dry matter expressed as percentage of intake) and (b) flavonol plasma concentration (i.e. quercetin, isorhamnetin and tamarixetin) of rats $1 \mathrm{~h}$ after administration of $5 \mathrm{~g}$ test meals that differed in their fat content and/or fatty acid pattern. All test meals contained approximately $100 \mu \mathrm{mol}$ quercetin/kg body weight. Values are means for six rats, with standard errors of the mean represented by vertical bars. For composition of diets, see Table 1. ( $\square$ ) Standard diet; ( $\square$ ) long-chain fatty acid triacylglycerol (LCT) diet; ( $\square$ ) medium-chain fatty acid triacylglycerols (MCT) diet. absorbed in the small intestine, like quercetin-3-O-glucoside. Effects of dietary co-ingestion of either LCT or MCT compared to a low-fat diet on the relative systemic availability of quercetin aglycone were investigated. In principle, the results obtained agree with the observations in the previous study (Lesser et al. 2004). Again, the co-administration of dietary fat enhanced the bioavailability of quercetin in pigs. Compared to the previous study, however, the stimulatory effect of the LCT diet was less pronounced and failed to meet the level of significance. The AUC obtained for quercetin applied with MCT fat was significantly higher than with the LCT or standard diet. Quercetin absorption from the test meal containing MCT was substantially delayed, indicated by the relatively slow rise in plasma levels (Fig. 1) and the late $t_{\max }$ (Table 2).

One possible cause for this delay in quercetin absorption from the MCT diet could have been a delayed gastric emptying of the MCT diet. In the literature, the mode of action of MCT fat on gastric emptying is controversial. Some studies found that gastric emptying after intake of MCT or mediumchain fatty acids was more rapid than after intake of LCT or long-chain fatty acids in human subjects (Hunt \& Knox, 1968) and in rats (Harkins et al. 1964). Another study observed no difference in gastric emptying between LCT and MCT in rats (Maggio \& Koopmans, 1987), while other groups reported a retardation of gastric emptying by MCT in comparison to LCT. In rats, the gastric emptying of tridecanoylglycerol was found to be significantly slower than that of cocoa butter or rapeseed oil (Porsgaard et al. 2003). Pirk \& Skala (1970) observed retarded gastric emptying in both rats and man by X-ray observation after administration of an MCT mixture compared to a lard mixture. They also found a delay in complete evacuation time of the small intestine after administration of MCT.

We investigated gastric emptying in rats after consumption of specific experimental diets. Rats are a frequently used animal model for investigations on gastric emptying, as mentioned earlier, and were chosen in this experiment because of the easier handling of the greater number of animals required (here $n 18$ ) compared to pigs. Regulation of gastric emptying in rats and pigs in response to dietary fat seems to function similarly. Plasma levels of cholecystokinin (CCK), a major mediator in the complex interplay of nutritional, hormonal and neural factors regulating gastric emptying, were shown to increase, among other triggers, in response to ingestion or intraduodenal administration of LCT or long-chain fatty acids in rats and pigs (Lilja et al. 1984; Cuber et al. 1990; Lewis \& Williams, 1990; Hölzer et al. 1994). Intravenous (i.v.) injection of active CCK-8 peptide dose-dependently evokes pylorus contraction and reduces intragastric pressure in rats, thus slowing down gastric emptying (Adelson et al. 2004). In pigs, gastric emptying was also retarded in response to i.v. application of CCK-8 (Gregory et al. 1995), and i.v. application of a specific CCK peripheral receptor antagonist reduced inhibition of gastric emptying triggered by duodenal fat infusion (Rayner \& Miller, 1993).

At $1 \mathrm{~h}$ after intake of the test meals in the present investigation, that is at a time point where plasma levels of quercetin metabolites were distinctly different between pigs that had ingested the LCT or MCT diet, no diet-related differences in gastric emptying were observed. The results obtained at this 
specific time point do not allow conclusions to be drawn regarding the impact of MCT $v$. LCT diet on gastric emptying in general. However, they do indicate that the delayed quercetin absorption from the MCT diet is probably not explained by slower gastric emptying. Some authors (Hopman et al. 1984; $\mathrm{Vu}$ et al. 1999) observed that, in contrast to LCT, dietary $\mathrm{MCT}$ do not induce CCK release in man. Because CCK inhibits gastric motility, a decrease in CCK secretion would result in enhanced gastric emptying and thus cannot explain the results obtained in the present study.

We also analysed the plasma flavonol levels at $1 \mathrm{~h}$ after meal intake and found that flavonol levels in rat plasma tended to be lower with the MCT diet. This was in accordance with the respective $1 \mathrm{~h}$ values in pigs, where we observed a significant difference (Fig. $1 ; P<0.05$ ). This might indicate that absorption of quercetin was also delayed from the MCT diet in rats, even though quercetin absorption may already have occurred from rat stomach (Crespy et al. 2002).

Although the MCT and LCT fat differ somewhat regarding their melting temperature (lard $26-39^{\circ} \mathrm{C}, \mathrm{C} 8: 016 \cdot 3^{\circ} \mathrm{C}$, $\left.\mathrm{C} 10: 031 \cdot 3^{\circ} \mathrm{C}\right)$, it can be assumed that both fats are fluid at body temperature. Conjugated bile acids are essential for the formation of mixed micelles, which enhance the absorption of fat-soluble substances, including molecules deriving from luminal triacylglycerol hydrolysis. The fairly lipophilic quercetin molecule might dissolve in the lipid phase of the chyme and mucosal uptake seems to be promoted in the presence of micelles (Azuma et al. 2002), as indicated presumably by the accelerated absorption of quercetin from a lard-containing diet, compared with a low-fat diet, found in the previous study (Lesser et al. 2004). As mentioned earlier, some authors (Hopman et al. 1984; Vu et al. 1999) observed that, in contrast to LCT, dietary MCT do not induce CCK release with subsequent gallbladder contractions in man. Thus, it can be assumed that in pigs, after ingestion of the MCT-containing diet, an emulsion without formation of mixed micelles will be present in the small intestinal contents. This might be one reason for the delayed absorption of quercetin from the MCT diet compared with the LCT-containing meal. It is known from certain drugs that their solubilization differs during lipolysis of LCT $v$. MCT (Christensen et al. 2004). However, we do not know how quercetin behaves in this respect. In another study, the hydrophobic drug cyclosporin A was dissolved in a solvent containing either MCT or LCT, which was infused intrajejunally in dogs. The appearance of this drug in portalvenous blood was significantly delayed when it was administered together with MCT, probably because no mixed micelles were formed, in contrast to LCT (Behrens et al. 1996). However, total absorption of cyclosporin A was significantly decreased with MCT, whereas in the present study the bioavailability of quercetin was increased when administered with the MCT diet.

An explanation for the delayed absorption of quercetin from the MCT diet compared to the LCT or standard diet could be a shift in quercetin absorption from the duodenum to more distal parts of the small intestine, due to physico-chemical factors. This hypothesis is in contrast to the general opinion that MCT are digested and absorbed faster than LCT (Metges \& Wolfram, 1991). However, some studies reported an acceleration of duodenocecal transit time during administration of MCT fat (Ledeboer et al. 1995; Verkijk et al. 1997). Vu et al. (1999) suggested that MCT, rather than LCT, might not be rapidly absorbed in the proximal gut but probably reached the ileocolonic region. An accelerated transit of quercetin-containing chyme through the duodenum and proximal jejunum after ingestion with the MCT diet, combined with a lower absorption from the proximal small intestine (due to solution in the lipophilic phase), could have shifted absorption of the flavonol to more distal segments of the small intestine. Assuming a more lipophilic nature of the chyme in the distal small intestine after MCT intake, a prolonged and intensified absorption of quercetin that resulted in higher accumulation in plasma could be feasible. In this context it is of interest that another lipid-soluble substance, vitamin E, showed an enhanced bioavailability when administered with MCT in comparison to LCT (Gallo-Torres et al. 1978).

Although the rats ingested a quercetin dosage only about three times higher than that applied to pigs, plasma levels after $1 \mathrm{~h}$ were at least ten times higher in rats. In addition, the pattern of methylated metabolites was also different between the two species. The higher proportion of isorhamnetin found in rat plasma in comparison to pig plasma might be due to a higher methylation activity exerted by catechol$O$-methyltransferase (EC 2.1.1.6). These observations are in good agreement with findings from other groups (Manach et al. 1996; de Boer et al. 2005). Thus, the methylation pattern of quercetin metabolites in pigs seems to be more similar to that in man (Hubbard et al. 2003) than in rats.

Although the unexpected finding of a delayed quercetin absorption with the MCT diet somewhat hampered the interpretation of the data with regard to the impact of either solubility within the chyme or integration into chylomicrons on quercetin bioavailability, we observed an enhanced bioavailability of the flavonol quercetin when administered with a diet containing moderate amounts of fat (either MCT of LCT). In general, however, human diets, especially those of a western type, contain by far enough fat to support the absorption of flavonols. Thus, only in the case of diets or meals extremely low in dietary fat might a moderate fat supply improve the bioavailability of quercetin.

\section{Acknowledgements}

We are grateful to the German Research Foundation (DFG) for funding this study by grant no. WO 763/2-3, and for supporting S.L. with a fellowship at the Research Training Group GRK820 at the University of Kiel. We are also grateful to Dr Silvia Wein, Maike Jürgensen, Dr Judith Ringel and Clemens Benthin for their support.

\section{References}

Adelson DW, Million M, Kanamoto K, Palanca T \& Taché Y (2004) Coordinated gastric and sphincter motility evoked by intravenous CCK-8 as monitored by ultrasonomicrometry in rats. Am J Physiol 286, G321-G332.

Ader P, Wessmann A \& Wolffram S (2000) Bioavailability and metabolism of the flavonol quercetin in the pig. Free Radic Biol Med 28, 1056-1067.

Almond GW (1996) Research applications using pigs. Vet Clin North Am Food Anim Pract 12, 707-716. 
Ausschuss für Bedarfsnormen der Gesellschaft für Ernährungsphysiologie. (1987) Energie- und Nährstoffbedarf landwirtschaftlicher Nutztiere Nr. 4 Schweine. Frankfurt a.M.: DLG-Verlag.

Azuma K, Ippoushi K, Ito H, Higashio H \& Terao J (2002) Combination of lipids and emulsifiers enhances the absorption of orally administered quercetin in rats. J Agric Food Chem 50, 1706-1712.

Behrens D, Fricker R, Bodoky A, Drewe J, Harder F \& Heberer M (1996) Comparison of cyclosporin A absorption from LCT and MCT solutions following intrajejunal administration in conscious dogs. J Pharm Sci 85, 666-668.

Belitz H-D \& Grosch W (1992) Lehrbuch der Lebensmittelchemie, 4th ed. Berlin: Springer Verlag.

Bloom B, Chaikoff IL \& Reinhardt WO (1951) Intestinal lymph as pathway for transport of absorbed fatty acids of different chain lengths. Am J Physiol 166, 451-455.

Cermak R, Landgraf S \& Wolffram S (2003) The bioavailability of quercetin in pigs depends on the glycoside moiety and on dietary factors. J Nutr 133, 2802-2807.

Christensen JO, Schultz K, Mollgaard B, Kristensen HG \& Mullertz A (2004) Solubilisation of poorly water-soluble drugs during in vitro lipolysis of medium- and long-chain triacylglycerols. Eur J Pharm Sci 23, 287-296.

Crespy V, Morand C, Besson C, Manach C, Demigné C \& Rémésy C (2002) Quercetin, but not its glycosides, is absorbed from the rat stomach. J Agric Food Chem 50, 618-621.

Cuber JC, Bernard C, Levenez F \& Chayvialle JA (1990) Lipids, proteins and carbohydrates stimulate the secretion of intestinal cholecystokinin in the pig. Reprod Nutr Dev 30, 267-275.

de Boer VCJ, Dihal AA, van der Woude H, Arts ICW, Wolffram S, Alink GM, Rietjens IMCM, Keijer J \& Hollman PCH (2005) Tissue distribution of quercetin in rats and pigs. J Nutr 135, 1718-1725.

Gallo-Torres HE, Ludorf J \& Brin M (1978) The effect of mediumchain triglycerides on the bioavailability of vitamin E. Int $J$ Vitam Nutr Res 48, 240-241.

Gregory PC, McFadyen M \& Rayner DV (1995) Control of gastric emptying in the pig: influence of cholecystokinin, somatostatin and prokinetic agents. Exp Physiol 80, 159-165.

Harkins RW, Longenecker JB \& Sarett HP (1964) The effect of the type and level of dietary fat on gastric retention in rats. Gastroenterology 47, 65-71.

Harkins RW \& Sarett HP (1968) Medium-chain triglycerides. J Am Med Assoc 203, 272-274.

Hashim SA, Bergen SS, Krell K \& Van Itallie TB (1964) Intestinal absorption and mode of transport in portal vein of medium chain fatty acids. J Clin Invest $\mathbf{4 3}, 1238$.

Herrmann K (1988) On the occurrence of flavonol and flavone glycosides in vegetables. Z Lebensm Unters Forsch 186, 1-5.

Hertog MGL, Hollman PCH \& Katan MB (1992) Content of potentially anticarcinogenic flavonoid of 28 vegetables and 9 fruits commonly consumed in The Netherlands. J Agric Food Chem 40, 2379-2383.

Hollman PCH, van Trijp JMP \& Buysman MNCP (1996) Fluorescence detection of flavonols in HPLC by postcolumn chelation with aluminum. Anal Chem 68, 3511-3515.

Hollman PCH, van Trijp JMP, Buysman MNCP, van der Gaag MS, Mengelers MJB, de Vries JHM \& Katan MB (1997) Relative bioavailability of the antioxidant flavonoid quercetin from various foods in man. FEBS Lett 418, 152-156.

Hölzer HH, Turkelson CM, Solomon TE \& Raybould HE (1994) Intestinal lipid inhibits gastric emptying via CCK and a vagal capsaicinsensitive afferent pathway in rats. Am J Physiol 267, G625-G629.

Hopman WPM, Jansen JBMJ, Rosenbusch G \& Lamers CBHW (1984) Effect of equimolar amounts of long-chain triglycerides and medium-chain triglycerides on plasma cholecystokinin and gallbladder contraction. Am J Clin Nutr 39, 356-359.

Hubbard GP, Wolffram S, Lovegrove JA \& Gibbins JM (2003) The role of polyphenolic compounds in the diet as inhibitors of platelet function. Proc Nutr Soc 62, 469-478.

Hunt JN \& Knox MT (1968) A relation between the chain length of fatty acids and the slowing of gastric emptying. $J$ Physiol 194, 327-336.

Ledeboer M, Masclee AAM, Jansen JBMJ \& Lamers CBHW (1995) Effect of equimolar amounts of long-chain triglycerides and medium-chain triglycerides on small-bowel transit time in humans. JPEN J Parenter Enteral Nutr 19, 5-8.

Lesser S, Cermak R \& Wolffram S (2004) Bioavailability of quercetin in pigs is influenced by the dietary fat content. $J$ Nutr 134, 1508-1511.

Lewis LD \& Williams JA (1990) Regulation of cholecystokinin secretion by food, hormones, and neural pathways in the rat. Am J Physiol 258, G512-G518.

Lilja P, Wiener I, Inoue K, Fried GM, Greeley GH Jr \& Thompson JC (1984) Release of cholecystokinin in response to food and intraduodenal fat in pigs, dogs and man. Surg Gynecol Obstet 159, $557-561$.

Maggio CA \& Koopmans HS (1987) Satiety effects of intragastric meals containing triglycerides with different chain lengths. Am J Physiol 252, R1106-R1113.

Manach C, Mazur A \& Scalbert A (2005) Polyphenols and prevention of cardiovascular diseases. Curr Opin Lipidol 16, 77-84.

Manach C, Texier O, Régérat F, Agullo G, Demigné C \& Rémésy C (1996) Dietary quercetin is recovered in rat plasma as conjugated derivates of isorhamnetin and quercetin. J Nutr Biochem 7, $375-380$.

Morand C, Crespy V, Manach C, Besson C, Demigné C \& Rémésy C (1998) Plasma metabolites of quercetin and their antioxidant properties. Am J Physiol 275, R212-R219.

Metges CC \& Wolfram G (1991) Medium- and long-chain triglycerides labeled with 13C: a comparison of oxidation after oral or parenteral administration in humans. J Nutr 121, 31-36.

Middleton E, Kandaswami C \& Theoharides TC (2000) The effects of plant flavonoids on mammalian cells: implications for inflammation, heart disease, and cancer. Pharmacol Rev 52, 673-751.

Murota K \& Terao J (2003) Antioxidative flavonoid quercetin: implication of its intestinal absorption and metabolism. Arch Biochem Biophys 417, 12-17.

Murota K \& Terao J (2005) Quercetin appears in the lymph of unanesthetized rats as its phase II metabolites after administered into the stomach. FEBS Lett 579, 5343-5346.

Pirk F \& Skala I (1970) Motility of the digestive tract after administration of medium chain triglycerides (MCT) as compared with long chain triglycerides (LCT). Digestion 3, 73-80.

Porsgaard T, Straarup EM \& Hoy CE (2003) Gastric emptying in rats following administration of a range of different fats measured as acetaminophen concentration in plasma. Ann Nutr Metab 47, $132-138$.

Rayner DV \& Miller S (1993) Voluntary intake and gastric emptying in pigs: effects of fat and a CCK inhibitor. Physiol Behav 54, 917-922.

Verkijk M, Vecht J, Gielkens HA, Lamers CBHW \& Masclee AAM (1997) Effects of medium-chain and long-chain triglycerides on antroduodenal motility and small bowel transit time in man. Dig Dis Sci 42, 1933-1939.

Vu MK, Verkijk M, Muller ESM, Biemond I, Lamers CBHW \& Masclee AAM (1999) Medium chain triglycerides activate distal but not proximal gut hormones. Clin Nutr 18, 359-363. 